\title{
Mindfulness as a Protective Factor Against Increased Tobacco and Alcohol Use in Hospital Workers Following the First COVID-19-Related Lockdown: a Study in Southern France
}

\author{
Tangui Barré ${ }^{1}$. Clémence Ramier ${ }^{1} \cdot$ Izza Mounir $^{2} \cdot$ Renaud David $^{3} \cdot$ Loick Menvielle $^{4}$. \\ Fabienne Marcellin ${ }^{1,5}$ (D) Patrizia Carrieri ${ }^{1} \cdot$ Camelia Protopopescu $^{1} \cdot$ Faredj Cherikh $^{1,2}$
}

Accepted: 11 December 2021

(c) The Author(s), under exclusive licence to Springer Science+Business Media, LLC, part of Springer Nature 2021

\begin{abstract}
COVID-19-related national lockdowns worldwide have had repercussions on people's well-being and have led to increased substance use. Mindfulness has previously been associated with reduced psychological distress and benefits in terms of addictive behaviors. We aimed to assess whether dispositional mindfulness protected against increased tobacco and alcohol use in hospital workers after France's first lockdown started. All workers in two French hospitals were contacted by email to participate in an online survey. Three hundred eighty-five workers answered. We ran two separate logistic regression models to test for associations between the level of dispositional mindfulness and both increased tobacco and alcohol use, after adjusting for affect deterioration. Dispositional mindfulness was associated with a lower likelihood of increased tobacco (adjusted odds ratio (AOR) [95\% CI] $0.71[0.51 ; 0.99], p=0.046)$ and alcohol $(0.66$ [0.50; 0.87], $p=0.004)$ use. The effect of mindfulness on tobacco use was partially mediated by affect deterioration. Dispositional mindfulness appeared to be a protective factor against lockdown-related tobacco and alcohol use increases in French hospital workers.
\end{abstract}

Keywords COVID-19 - Mindfulness · Tobacco · Alcohol · Addictive behavior · Psychological distress

Fabienne Marcellin

fabienne.marcellin@inserm.fr

1 Aix Marseille Univ, Inserm, IRD, SESSTIM, Sciences Economiques \& Sociales de la Santé \& Traitement de L'Information Médicale, ISSPAM, 27 Bd Jean Moulin, 13385 Cedex 5 Marseille, France

2 Addictology Unit, University Hospital of Nice, Archet 2 Hospital, 151 Route de Saint-Antoine, 06200 Nice, France

3 Centre Hospitalier Universitaire de Nice, Centre Mémoire de Ressources Et de Recherche, Institut Claude Pompidou, 10 rue Molière, 06100 Nice, France

4 EDHEC School, 393 Prom. des Anglais, 06200 Nice, France

5 SESSTIM, Faculté de Médecine de La Timone, aile bleue, 27 Bd Jean Moulin, 13385 Cedex 5 Marseille, France 
In March 2020, Europe was labeled the epicenter of the coronavirus disease 2019 (COVID19) pandemic (Adhanom Ghebreyesus, 2020). National lockdowns were subsequently implemented in several European countries, including France, in order to slow its spread. Despite their epidemiological benefits (Alfano \& Ercolano, 2020), these (often recurrent) lockdowns had a negative impact on the mental health and well-being of populations, including children (Panda et al., 2021), students (Evans et al., 2021), the general population (Fiorillo et al., 2020; Xiong et al., 2020), healthcare workers (Chatzittofis et al., 2021; Lange et al., 2021; Vizheh et al., 2020), and hospital staff (Ali et al., 2020; Jo et al., 2020; Mattila et al., 2021). In the ongoing pandemic context, increased tobacco and alcohol use (Gendall et al., 2021; Jacob et al., 2021; Vanderbruggen et al., 2020) has been observed in the general population; this is probably partly due to coping strategies to manage psychological distress (Chodkiewicz et al., 2020; Grogan et al., 2020; Wardell et al., 2020).

Dispositional mindfulness (the propensity to be mindful in everyday life) has been highlighted as a potential protective factor against psychological distress during the COVID19 pandemic (Conversano et al., 2020). Mindfulness can be defined as a process involving attention, awareness, and open-minded acceptance of the present moment (Garland $\&$ Howard, 2018). Mindfulness qualities such as accepting and remaining nonreactive to distressful thoughts and emotions have been identified as possible antidotes to addictive behaviors (Garland \& Howard, 2018). Furthermore, mindfulness-based interventions have yielded promising results in the domain of substance use disorders in general (Li et al., 2017), and specifically for tobacco (Maglione et al., 2017) and alcohol (Byrne et al., 2019; Kamboj et al., 2017) use disorders. With regard to observational studies, dispositional mindfulness was negatively associated with craving for tobacco smoking in 350 students (Nosratabadi et al., 2017), and seemed to reduce cued alcohol cravings in 240 young adults (Karyadi et al., 2014). To date, studies on mindfulness focusing on health and hospital workers have mostly focused on well-being or burnout (Hall et al., 2016; McFarland \& Hlubocky, 2021); very few have addressed substance use (Altner, 2002). However, as mindfulness-based interventions seem acceptable for this population (Rodriguez-Vega et al., 2020) and have been proven cost-effective in some contexts (Müller et al., 2019), there is a need to determine whether targeting dispositional mindfulness may impact substance use in health workers chronically exposed to stress. Our objective was to test whether dispositional mindfulness may have been a protective factor against increased tobacco and alcohol use in a sample of hospital healthcare workers in the context of the first COVID-19-related national lockdown in France (17 March-11 May 2020).

\section{Material and Methods}

\section{Survey Design}

Data were taken from an ad hoc cross-sectional anonymous online survey which we launched on 28 April 2020 and closed on 8 June 2020. The survey aimed to study the impact of the COVID-19 pandemic on hospital workers. The questionnaire was constructed and submitted using a Google survey form. An invitation via hyperlink was sent to all workers in two public hospitals in Nice (Southern France) who had a professional e-mail address $(n=9300)$. The only criterion for inclusion was being employed in one of the hospitals. We expected a response rate of $10 \%$, leading to an expected sample size of 
930. The survey was conducted in accordance with the Declaration of Helsinki. In line with French law, no consent was required since the survey was anonymous.

\section{Measures}

The following data were collected to describe participants' characteristics at the time of the survey: gender, age group, profession, type of housing, household composition, history of depression, lockdown-related drop in income, and dispositional mindfulness, which was assessed using the Mindful Attention Awareness Scale (MAAS). The MAAS is a 15-item, single-factor structured scale (Brown \& Ryan, 2003; Carlson \& Brown, 2005; Jermann et al., 2009). Each item is scored between 1 and 6 . The overall score is the mean of the scores for the 15 items, with a higher value denoting greater mindfulness.

In addition, the following question was asked with reference to two distinct periods, specifically pre-lockdown and after the lockdown started: "Did (Do) you do physical activity?" There were four possible answers: "Yes, less than $30 \mathrm{~min}$ per day," "Yes, 30 to $60 \mathrm{~min}$ per day," "Yes, more than an hour per day," or "No, I did (do) not do any physical activity." For the same two periods, participants were also invited to individually rate the following five affect indicators on a scale from 0 to 5: sleep quality, motivation, stress, irritability, and sadness. These five items were built ad hoc to capture changes in affect and feelings (irrespective of the absolute value of each item). We subsequently tested for the unidimensionality of the items (see "Model Outcomes and Explanatory variables"). The Fagerström Test for Nicotine Dependence (Etter et al., 1999; Heatherton et al., 1991) was also administered with reference to both periods.

Finally, the following question was asked to first assess tobacco and then alcohol use status: "Since the beginning of the lockdown, your consumption of [tobacco/alcohol] ...," with the following five possible answers: "has been identical," "has decreased," "has increased," "I stopped consuming it," and "I do not consume it."

\section{Statistical Analysis}

\section{Model Outcomes and Explanatory Variables}

The following two binary outcomes were considered in the study models: "increased tobacco use" (yes/no) and "increased alcohol use" (yes/no) since the beginning of the lockdown. Tobacco users, defined as participants who did not answer "I do not consume it" to the tobacco-related question, were categorized as having increased tobacco use or not having increased tobacco use (i.e., stable or decreased use, the latter including smoking cessation). Similarly, alcohol consumers, defined as participants who did not declare "I do not consume it" to the alcohol consumption question, were categorized as having increased alcohol use or not having increased alcohol use (i.e., stable or decreased use, the latter including alcohol cessation).

The following potential explanatory variables were tested: the MAAS score of dispositional mindfulness, gender, age group, profession, type of housing, household composition, history of depression, lockdown-related drop in income, change in physical activity, and change in sleep quality, motivation, stress, irritability, and sadness, as well as pre-lockdown nicotine dependence. Age group was self-reported by ticking one of the following options: 18-30, 31-40, 41-50, 51-65, and $65+$ years of age. The two older groups were merged due to low numbers. Profession was recorded using 
a multiple-choice question plus a free text option. It was subsequently coded under "direct contact profession other than physicians" (this modality included nurses, nurse assistants, psychologists, adapted physical activity leaders, social workers, dentists, pharmacists, midwives), "administration," "engineering, logistics and technical functions" (including information technology personnel, hospital engineering personnel, laboratory technicians), and "physician" (including internal medicine doctors, general practitioners, and specialists). Change in physical activity was coded into "decreased" (i.e., reporting more physical activity before the lockdown started) and "not decreased" (i.e., unchanged or more activity since the lockdown started).

Changes in self-reported sleep quality, motivation, stress, irritability, and sadness were separately coded under "deterioration" (i.e., a higher scale score (see above) for before the lockdown than after it started for sleep quality and motivation, and a higher score after the lockdown started for stress, irritability, and sadness) and "no deterioration" (i.e., lower scale scores). We hypothesized that these five affect deterioration items constituted different components of a composite measure of change (whether desirable or undesirable) in affect and feelings for each participant. Accordingly, we tested for unidimensionality by performing a multiple correspondence analysis (MCA) (Sourial et al., 2010). Using the analysis' results, we built a composite variable for change in affect and feelings.

\section{Descriptive Statistics and Statistical Models}

The study population's characteristics were described using median [interquartile range (IQR)] and frequency and percentages, respectively, for continuous and categorical variables. MAAS scores were compared between participants according to the different modalities of categorical variables (see above) using the Kruskal-Wallis test. Smokers' and alcohol drinkers' characteristics were compared, respectively, with those of non-smokers and non-drinkers using a chi-square (categorical variables) or a Kruskal-Wallis (continuous variables) test. Cronbach's alpha was estimated for MAAS and Fagerström Test for Nicotine Dependence. Logistic regression models were used to test for associations between MAAS score and both tobacco- and alcohol-related outcomes, after adjustment for other potential predictors. Only variables with a liberal $p$ value $<0.20$ in the univariable analyses were considered eligible for the multivariable model (Hosmer \& Lemeshow, (n.d.)). The final multivariable model was built using a backward selection procedure. The likelihood ratio test $(p<0.05)$ was used to define the variables to maintain in the final model. Results from logistic regression models were presented as odds ratios (OR) and adjusted odds ratios (AOR) (for the multivariable model), with the corresponding 95\% confidence intervals (CI). The level of significance was set at $\alpha=0.05$ in all tests. Variables eligible for multivariable analyses but not retained in the final model were separately reintroduced into the final model to check the stability of results and to assess the magnitude of changes in odds ratio estimations. For both substances, we performed a sensitivity analysis by removing participants who reported decreased use from the study sample.

We hypothesized that dispositional mindfulness might have an effect on the outcomes through affect deterioration (i.e., a mediation effect) (Fig. 1). Accordingly, we decided that we would perform mediation analyses if both variables (i.e., mindfulness and affect) were maintained in the final model. All analyses were performed with Stata version 16.1 for Windows (StataCorp LP, College Station, TX). 


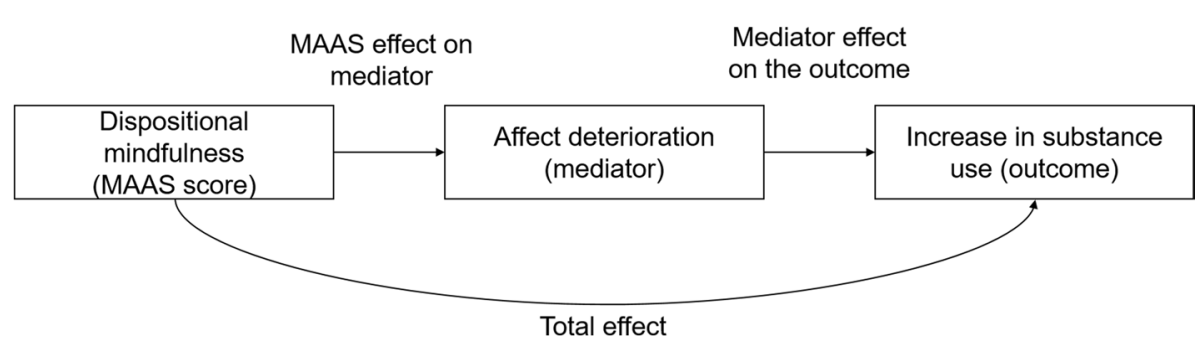

Fig. 1 Design of the mediation analysis

\section{Results}

\section{Composite Variable for Affect Deterioration}

The MCA confirmed the single dimension of the set of five affect deterioration variables (sleep quality, motivation, stress, irritability, and sadness) (97.4\% of total inertia for dimension 1). Accordingly, we were able to create a composite variable (ranging from 0 to 5) for affect deterioration, which equaled the sum of the five individual affect deterioration scores.

\section{Study Population Characteristics}

The study population's characteristics are provided in Table 1 . The response rate was of $7.5 \%$ ( $n=702$ respondents). Data from two participants were removed because they did not work in the participating hospitals. Of the remaining 700 participants, 385 declared using at least one of the two substances (i.e., alcohol or tobacco), 562 (80.3\%) were female and $398(56.9 \%)$ were $31-50$ years old. The profession category most represented was "direct contact profession other than physician," with 291 (41.6\%) participants. Data on tobacco use status, pre-lockdown nicotine dependence score, and alcohol use status were available for 698 (99.7\%), 129 (18.4\%), and 699 (99.9\%) participants, respectively. Less than a quarter $(22.8 \%)$ of the participants smoked before the lockdown started, while 334 (47.8\%) drank alcohol. Half the smokers (49.7\%) reported increased tobacco use after the lockdown started, and a third (34.7\%) of drinkers increased their alcohol use. Eleven percent and $23.4 \%$ of smokers and drinkers reported decreasing (or ceasing) their use, respectively. MAAS scores ranged from 1.3 to $6.0(\mathrm{M}=4.03, \mathrm{SD}=0.92)$, with a median [IQR] of 4.0 [3.4; 4.7]. Cronbach's alpha was 0.91 and 0.62 for the MAAS and Fagerström Test for Nicotine Dependence, respectively.

\section{Factors Associated with Increased Tobacco Use Since the Beginning of the Lockdown}

Table 2 provides the results from the univariable and multivariable analyses for the tobacco outcome. Consistent with the primary hypothesis, both affect deterioration (AOR [95\% $\mathrm{CI}]: 1.41[1.15 ; 1.73], z=3.34, p=0.001)$ and a lower MAAS score $(0.71$ [0.51;0.99], $z=-2.00, p=0.046$ ) were independently associated with increased tobacco use since the 


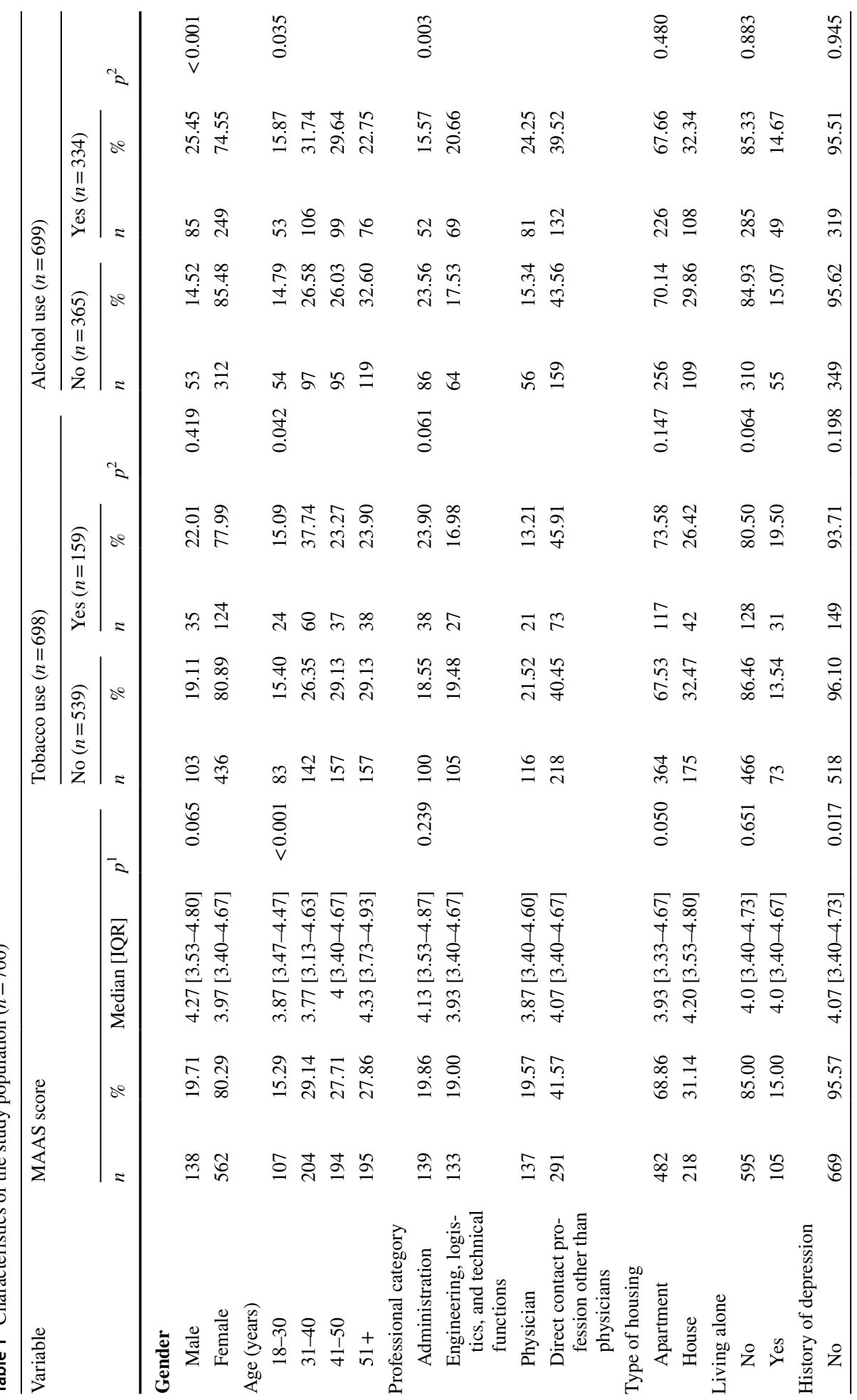




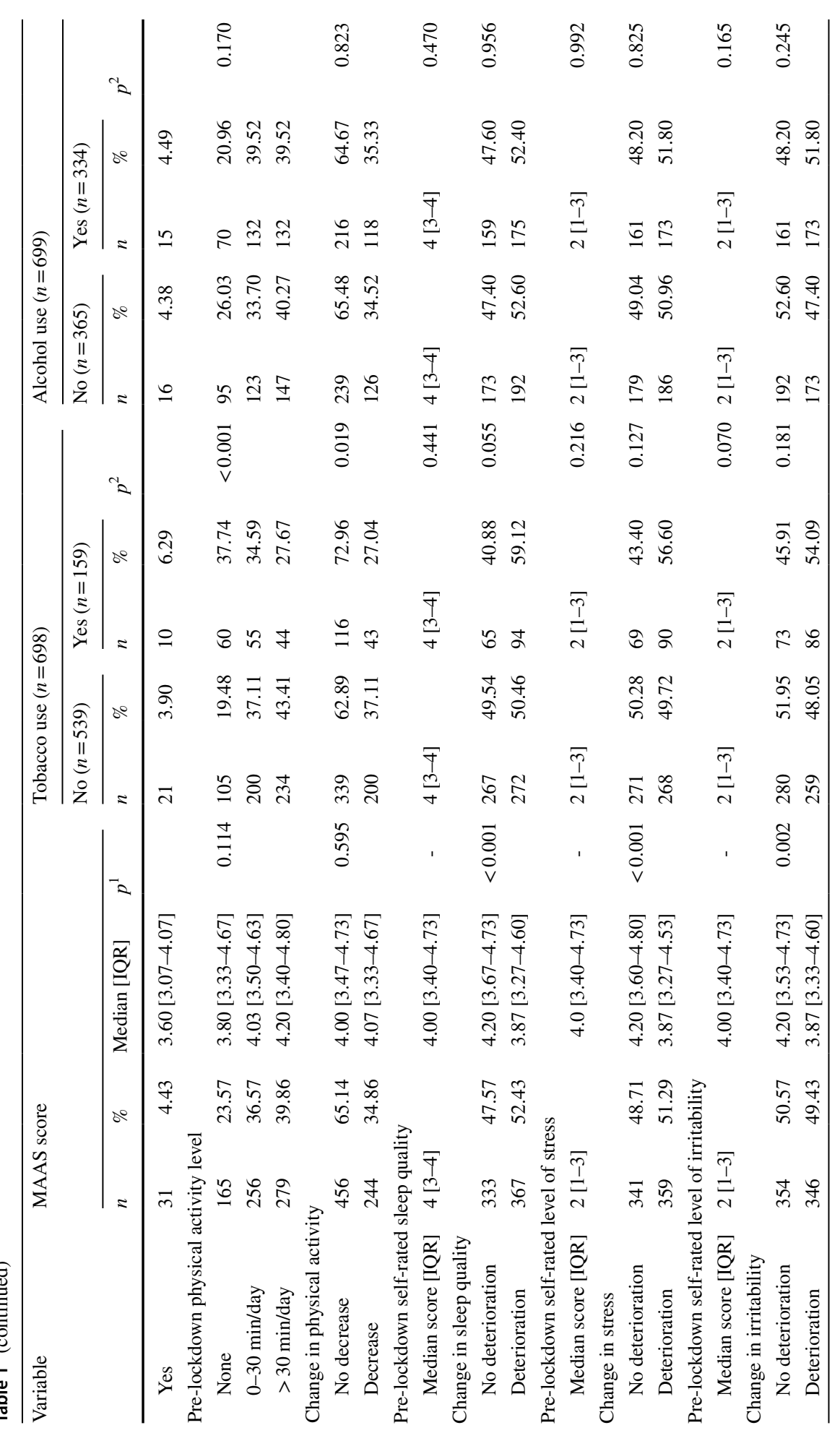




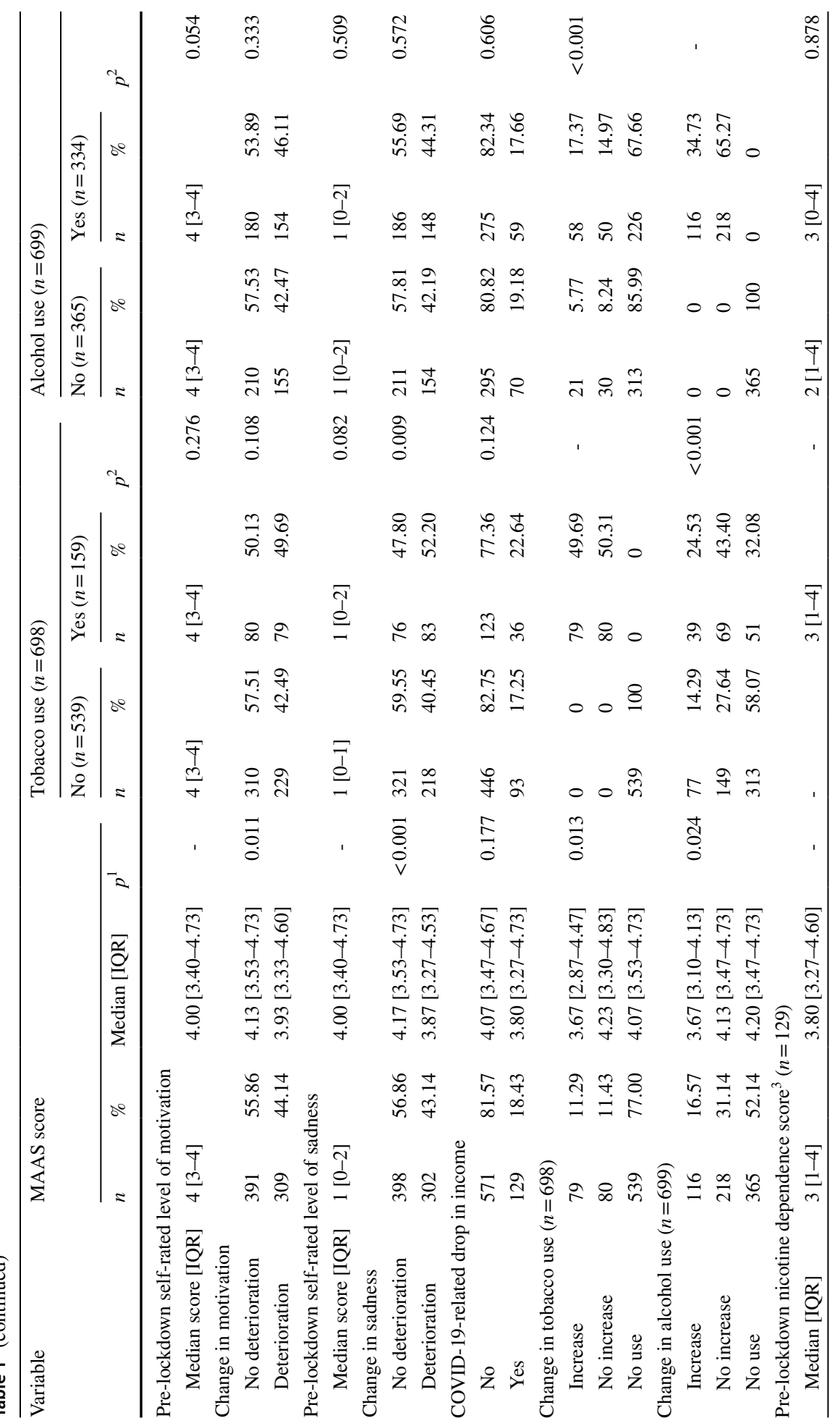




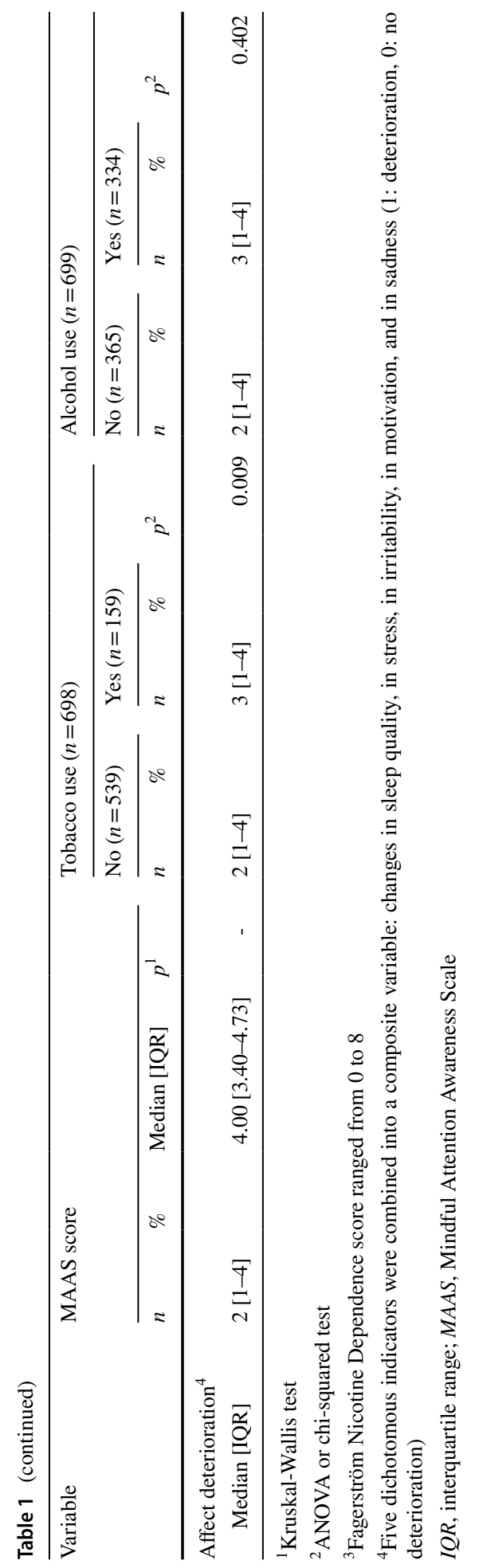




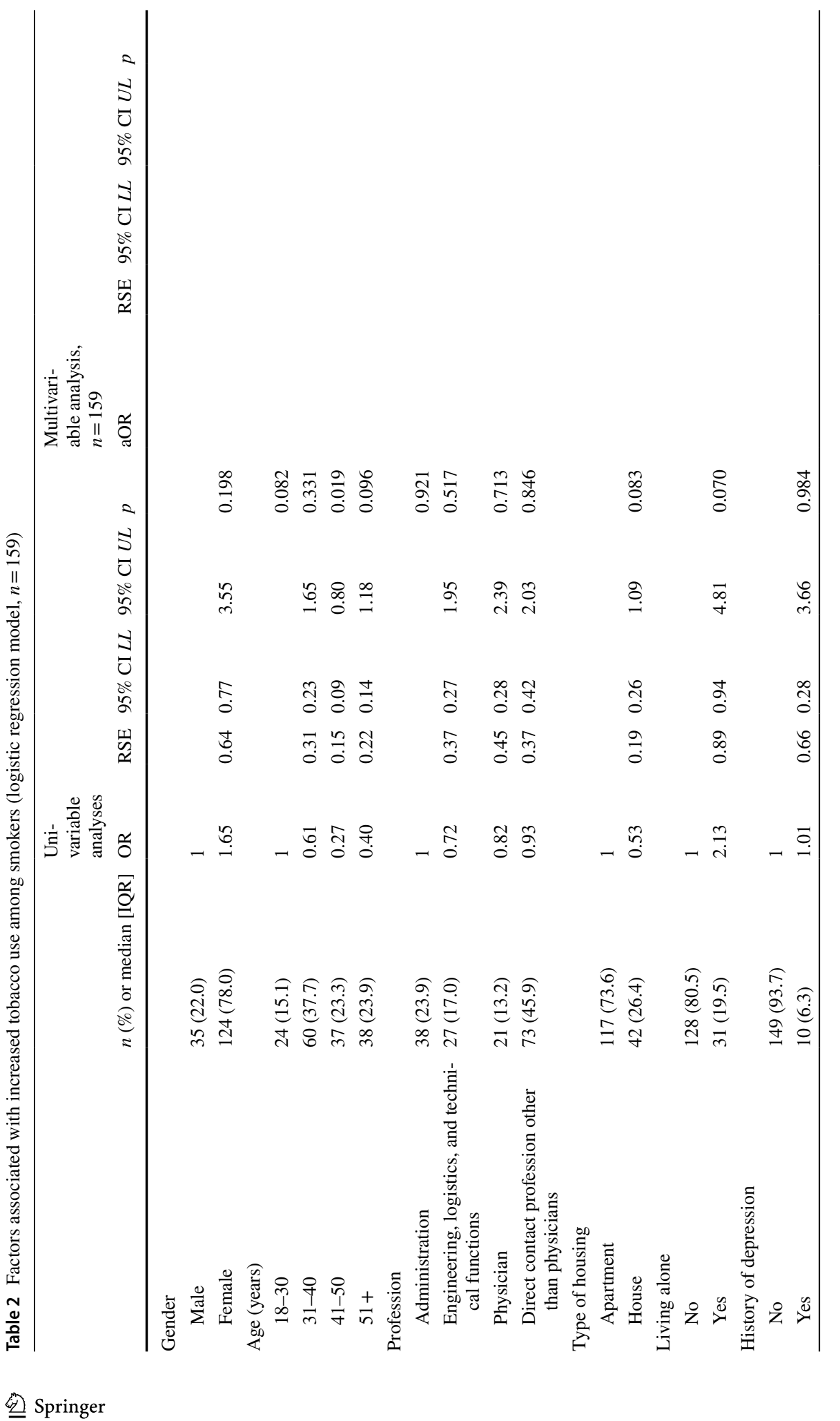




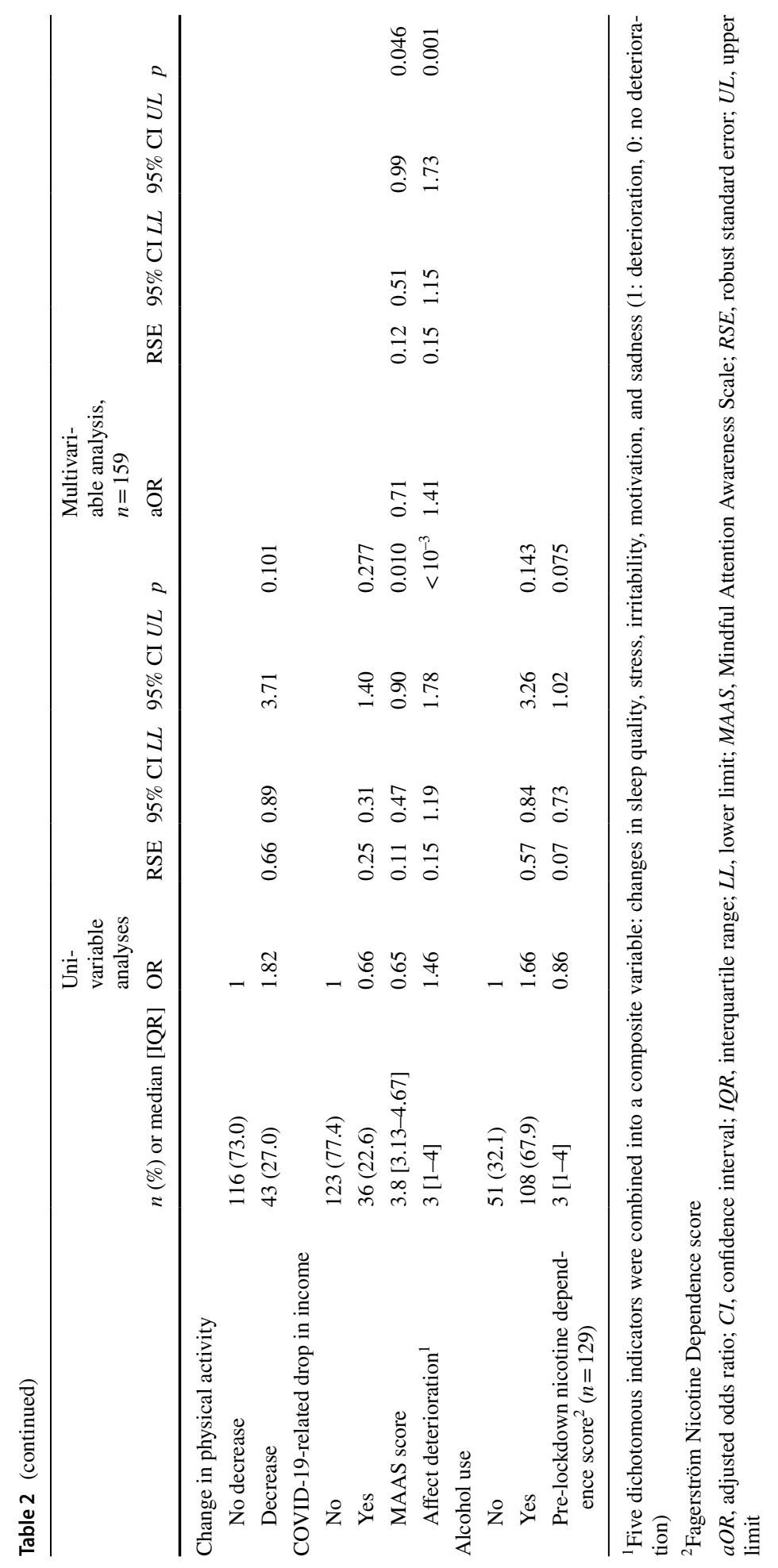


beginning of the lockdown. Reintroducing the discarded explanatory variables in the final model had no impact on estimates (data not shown). Similarly, sensitivity analyses provided comparable results (data not shown).

The mediation analysis (with affect deterioration as the mediator) (Fig. 1) highlighted that the MAAS score had a significant total effect on the outcome (logit regression coefficient $[95 \% \mathrm{CI}]:-0.43[-0.76 ;-0.10], z=-2.56, p=0.010)$, and a direct effect both on the outcome $(-0.34[-0.68 ;-0.01], p=0.046)$ and on the mediator (linear regression coefficient $[95 \% \mathrm{CI}]:-0.33[-0.60 ;-0.07], t(158)=-2.52, p=0.013)$. Affect deterioration had a significant effect on the outcome $(0.35[0.14 ; 0.55], z=3.34, p=0.001)$. Taking into account the mediating effect of affect deterioration, the average causal mediated effect of the MASS score on the outcome was $22 \%$.

\section{Factors Associated with Increased Alcohol Use Since the Beginning of the Lockdown}

Table 3 provides the results from the univariable and multivariable analyses for the alcohol outcome. Consistent with the primary hypothesis, MAAS score was inversely associated with increased alcohol use since the beginning of the lockdown in the final model (AOR [95\% CI]: 0.66 [0.50; 0.87], $z=-2.91, p=0.004$ ). However, affect deterioration was associated with the outcome only in the univariable analysis. Being aged $31-40$ years old (AOR [95\% CI]: 2.90 [1.37; 6.14], $z=2.79, p=0.005$ vs. $18-30$ years) was also independently associated with the outcome in the multivariable model. Reintroducing the discarded explanatory variables in the final model had no impact on the model estimates (data not shown). Similarly, sensitivity analyses led to comparable results (data not shown). A post hoc analysis, performed by removing the MAAS score from the model, led to a final model where age was the only variable associated with the outcome. The mediation analysis was not performed in this case, as affect deterioration was not significantly associated with the outcome in the multivariable analysis.

\section{Discussion}

In a population of 700 hospital workers in France, of whom 385 reported either tobacco or alcohol use, we found that a higher MAAS score for dispositional mindfulness was associated with a lower likelihood of both increased tobacco and alcohol use after the first national COVID-19-related lockdown began. For tobacco use, this effect was partly mediated by affect deterioration.

The latter result echoes findings elsewhere (Brooks et al., 2020), and confirms that the first lockdown - and by association, the COVID-19 pandemic itself-was most likely a source of psychological distress. It also suggests that tobacco and/or alcohol was used, at least in part, as a coping strategy, which is in line with Wardell et al.'s results in Canada. Those authors found that increased alcohol use following the onset of COVID-19-related emergency public health measures was associated with coping strategies (Wardell et al., 2020). Similarly, in the USA, Grossman et al. found that people who experienced COVID-19-related stress reported higher drinking levels, and that stress was the most quoted reason for increased drinking (Grossman et al., 2020). In a demographically representative sample of adults in New Zealand, Gendall et al. found that daily smokers who felt distressed during the country's only nationwide lockdown were more likely to have increased their tobacco use (Gendall et al., 2021). In France, 


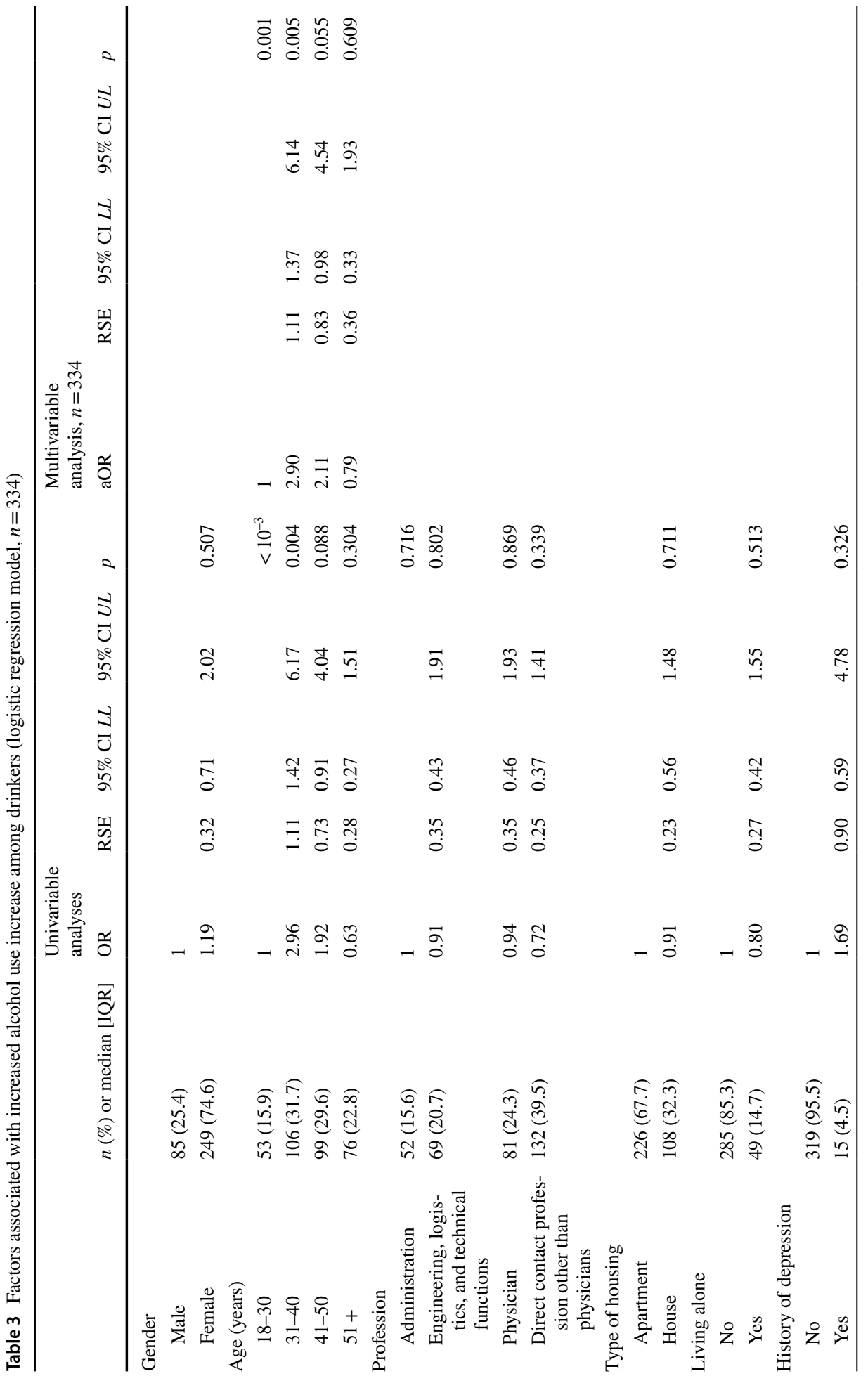




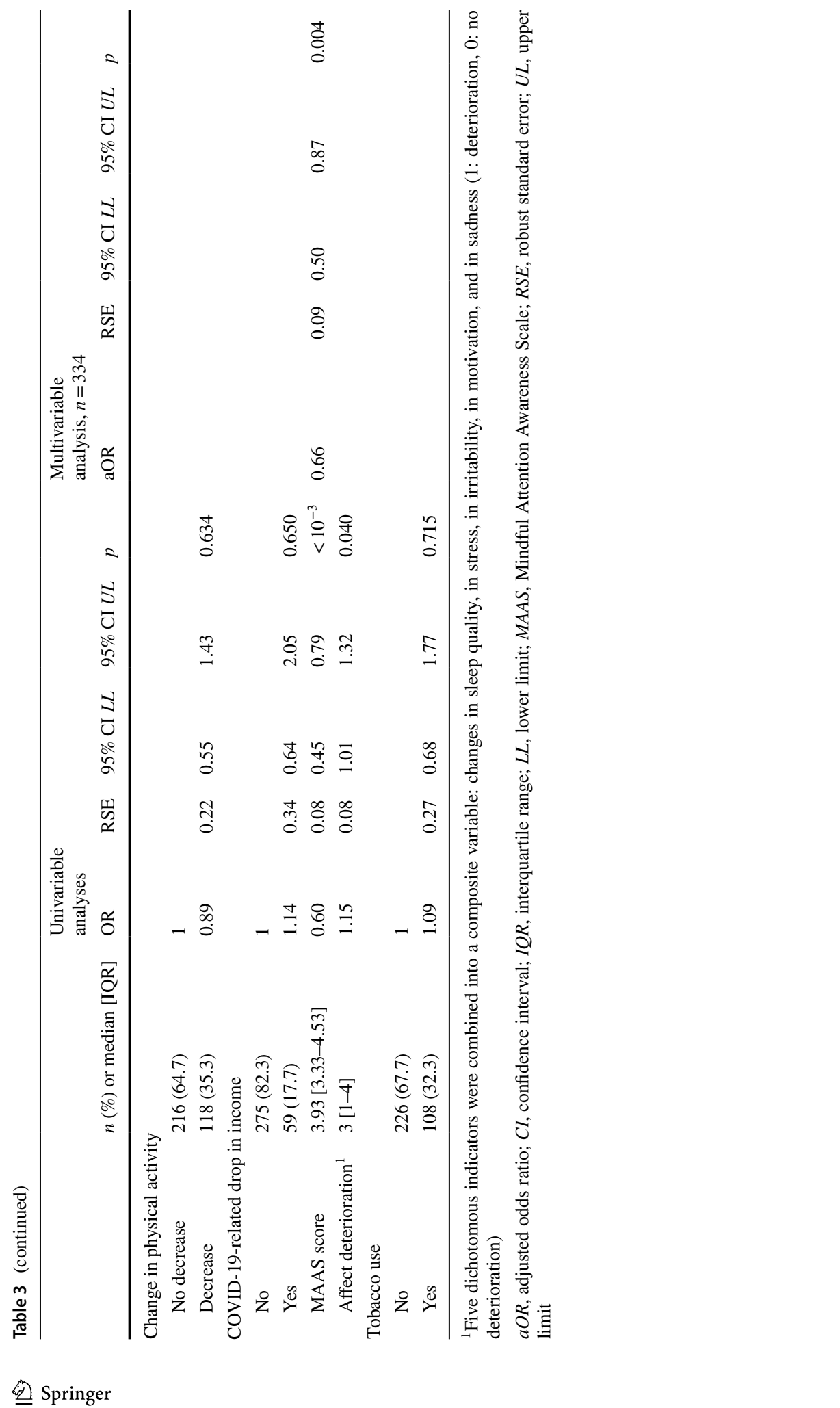


negative mental state changes were also strongly associated with alcohol consumption changes during the first lockdown (Rossinot et al., 2020). We confirmed this relationship, but only for tobacco, in our sub-population of hospital workers. Even when removing dispositional mindfulness from the model, affect deterioration did not predict increased alcohol use. One possible reason for this discrepancy is that our affect variable may not have adequately captured changes in stress or well-being. Another hypothesis is that for alcohol users, other reasons to increase drinking were predominantly at play, such as boredom (Grossman et al., 2020) and/or participating in online social gatherings, for example, aperitifs, using social media applications. Finally, easier access to tobacco than to alcohol may also have played a part, especially in the workplace. Specifically, while outdoor cigarette smoking during breaks is permitted in France, alcohol consumption at work is prohibited.

In the context of the first Italian lockdown, dispositional mindfulness was found to be the best predictor of psychological distress alongside socio-demographic variables (Conversano et al., 2020), and was negatively associated with worry and fear (Baiano, Zappullo, The LabNPEE Group, \& Conson, 2020). Similarly, in the context of COVID-19 in the USA, mindfulness was associated with distress (Dillard \& Meier, 2021). We found that mindfulness was negatively associated with increased tobacco and alcohol use after adjusting for affect deterioration. Moreover, the latter only partially mediated this effect for tobacco. This result suggests that the impact which mindfulness has on the use of these two legal substances may not only be mediated by psychological distress or emotion regulation (Freudenthaler et al., 2017; Lutz et al., 2014); it may act through other mechanisms such as perceptual ability and/or cognitive control (Anicha et al., 2012) or reduction of craving (Szeto et al., 2019; Tapper, 2018). Mindfulness increases early identification of problematic thoughts and feelings and in turn, this identification fosters the use of adaptive, flexible coping behaviors (Hanley et al., 2014; Jones et al., 2019) instead of maladaptive ones. In addition to enabling the implementation of adaptive responses to negative affect, mindfulness may also attenuate the usual affective bias that underlies emotional reactivity (Brewer et al., 2013). However, as mindfulness correlates with other traits such as impulsivity or anxiety (Black et al., 2012; Jaiswal et al., 2019; Peters et al., 2011), which are themselves linked to substance use (Kozak et al., 2019; Smith \& Book, 2008), we cannot exclude that the associations we reported between mindfulness and substance use changes may be explained by such other psychological traits.

Our results remained unchanged after excluding participants who reduced or quit their alcohol or tobacco use during the lockdown. This confirms that the protective effect which we found between mindfulness and substance use increase was not due to reducing or quitting use. A reduction in smoking in the context of COVID-19 was also highlighted in a different study which found that the pandemic prompted some smokers to adopt healthier smoking behaviors (Klemperer et al., 2020).

This beneficial impact of dispositional mindfulness on smoking behavior is in line with a study reporting better cessation outcomes in smokers with greater mindfulness at the beginning of a non-mindfulness-based smoking cessation intervention (Heppner et al., 2016). It also reflects findings from studies reporting a negative association between dispositional mindfulness and both craving for smoking (Nosratabadi et al., 2017) and current smoker status (Loucks et al., 2015). Similarly, in terms of alcohol use, greater dispositional mindfulness was associated with less craving in recovering alcohol-dependent patients, which in turn was associated with less alcohol consumption (Szeto et al., 2019). Observational data highlighting the putative benefits of dispositional mindfulness on substance use (Karyadi et al., 2014) were subsequently partially confirmed by mindfulness-based 
interventions targeting tobacco (Maglione et al., 2017; Oikonomou et al., 2017) and alcohol (Cavicchioli et al., 2018; Kamboj et al., 2017; Zgierska et al., 2019) use.

Hospital workers represent a population already at risk of stress and burnout which has been put under even greater pressure by the current pandemic (Clinchamps et al., 2021; Durand et al., 2019; Kansoun et al., 2019). In terms of COVID-19, studies elsewhere have already highlighted the negative impact of the pandemic on healthcare workers' mental health and well-being (Chatzittofis et al., 2021; Huang \& Zhao, 2020; Vizheh et al., 2020). Despite the poor representativity of our sample (e.g., women were overrepresented), the fact that we did not find differences in substance use changes between the five different profession types studied suggests that all were impacted by these stress-related changes. This lack of association echoes Mattila et al. who found that the level of anxiety among hospital staff in Finland during the COVID-19 pandemic was independent of their professional activity type, and whether they had direct or indirect contact with COVID-19 patients (Mattila et al., 2021).

Our results highlight the need for greater training in mindfulness for all hospital workers-whether healthcare professionals or not (Ruiz-Fernández et al., 2020; Spinelli et al., 2019) — both to increase their dispositional mindfulness and to limit the detrimental impact of stress (in turn limiting this impact on hospital patients) (Hall et al., 2016). For instance, most of the study respondents in a mindfulness-based intervention study, which was implemented for workers in a Spanish hospital during 2020 because of the COVID-19 pandemic, considered it helpful (Rodriguez-Vega et al., 2020).

An online French survey found that people aged 35-54 years old were more likely to increase their alcohol use during the country's first lockdown than people aged 25-34, but that the former group and those aged 55-64 were less likely to increase their tobacco use (Rossinot et al., 2020). The first result reflects our finding that younger age (18-30 versus $31-40)$ is a protective factor against increased alcohol use, while the second echoes our univariable analysis findings where younger age was a risk factor for increased tobacco use. Using a mental state indicator similar to our affect deterioration variable, Rossinot et al. found - just as we did - that a poorer mental state was associated with higher odds of tobacco use increase in the French general population, even after adjustment for age.

The absence of a gender effect on substance use changes before and after the first lockdown started would seem to contradict previous studies in both France and Italy which reported that lockdowns had a greater negative impact on women's well-being (Conversano et al., 2020; Haesebaert et al., 2020). Gender specificities regarding coping strategies may partly explain these unexpected results (Gemmell et al., 2016; Hobfoll et al., 1994), as well as the model adjustments we made for affect deterioration. Finally, a lack of statistical power cannot be excluded, as our study sample mainly comprised women.

To our knowledge, the present study is the first to highlight a link between dispositional mindfulness and changes in tobacco and alcohol use in hospital workers in the stressful context of the ongoing COVID-19 pandemic. The use of a validated measure of dispositional mindfulness, specifically the MAAS, and adjustment for survey participants' sociobehavioral characteristics are two important study strengths. We launched the online survey during the first lockdown, and therefore, our results should be directly related to this specific context.

Two study limitations deserve special attention. The first regards the measuring tools we used. Specifically, in order to simplify the questionnaire and keep it short, we did not administer standard, validated scales to measure psychological distress. Instead, we used visual analog scales as they are commonly employed and have been validated in similar domains of research (Cappelleri et al., 2009; de Boer et al., 2004). In addition, changes 
in substance use were self-reported; had we used a validated instrument like the Timeline Followback, result validity would have been ensured. Having said that, the results of the MCA we conducted confirmed the ability of our composite variable to adequately reduce five different affect indicators into a single variable. The second important limitation is that the study's cross-sectional design prevented us from collecting data for each variable before and after the lockdown started, thereby introducing the possibility of recall bias. However, the period between the start of the lockdown and the study was relatively short (3 months maximum) limiting any such bias.

\section{Conclusion}

Dispositional mindfulness appears to have been a protective factor against increased tobacco and alcohol use following the first COVID-19-related lockdown in French hospital workers. This result highlights the potential benefits of mindfulness-based interventions in preventing stress-associated detrimental addictive behaviors in stressful contexts. As the pandemic is still ongoing (as of November 2021), our results may encourage the rapid implementation of such interventions for hospital workers and other populations vulnerable to negative COVID-19-related changes in substance use.

Author Contribution Tangui Barré: conception and design, data analysis and interpretation, drafting the paper and critically revising it for intellectual content.

Clémence Ramier: data analysis and interpretation.

Faredj Cherikh: conception and design, critical revision of the paper for intellectual content.

Fabienne Marcellin: conception and design, data analysis and interpretation, critical revision of the paper for intellectual content.

Patrizia Carrieri: conception and design, data analysis and interpretation, critical revision of the paper for intellectual content.

Camelia Protopopescu: conception and design, data analysis and interpretation, critical revision of the paper for intellectual content.

Izza Mounir: conception and design, critical revision of the paper for intellectual content.

Renaud David: conception and design, critical revision of the paper for intellectual content.

Loic Menvielle: conception and design, critical revision of the paper for intellectual content.

\section{Declarations}

Ethics Approval According to French law and anonymity of data, no approval from ethics committee was needed.

Research Involving Human Participants and/or Animals All procedures followed were in accordance with the ethical standards of the responsible committee on human experimentation (institutional and national) and with the Helsinki Declaration of 1975, as revised in 2000.

Consent to Participate Informed consent was obtained from all patients for being included in the study.

Conflict of Interest The authors declare no competing interests.

\section{References}

Adhanom Ghebreyesus, T. (2020). WHO Director-General's opening remarks at the media briefing on COVID-19. Geneva: World Health Organization. Consulté à l'adresse World Health Organization 
website: https://www.who.int/director-general/speeches/detail/who-director-general-s-opening-remar ks-at-the-mission-briefing-on-covid-19---13-march-2020Access 18 March 2021

Alfano, V., \& Ercolano, S. (2020). The Efficacy of Lockdown Against COVID-19: A Cross-Country Panel Analysis. Applied health economics and health policy, 18(4), 509-517. https://doi.org/10.1007/ s40258-020-00596-3

Ali, S., Maguire, S., Marks, E., Doyle, M., \& Sheehy, C. (2020). Psychological impact of the COVID-19 pandemic on healthcare workers at acute hospital settings in the South-East of Ireland : An observational cohort multicentre study. British Medical Journal Open, 10(12), e042930. https://doi.org/10. 1136/bmjopen-2020-042930

Altner, N. (2002). Mindfulness practice and smoking cessation: The Essen Hospital Smoking Cessation Study (EASY). Journal for Meditation and Meditation Research, 1, 9-18.

Anicha, C. L., Ode, S., Moeller, S. K., \& Robinson, M. D. (2012). Toward a cognitive view of trait mindfulness : Distinct cognitive skills predict its observing and nonreactivity facets. Journal of Personality, 80(2), 255-285. https://doi.org/10.1111/j.1467-6494.2011.00722.x

Baiano, C., Zappullo, I., The LabNPEE Group, \& Conson, M. (2020). Tendency to Worry and Fear of Mental Health during Italy's COVID-19 Lockdown. International journal of environmental research and public health, 17(16), 5928. https://doi.org/10.3390/ijerph17165928

Black, D. S., Sussman, S., Johnson, C. A., \& Milam, J. (2012). Psychometric assessment of the Mindful Attention Awareness Scale (MAAS) among Chinese adolescents. Assessment, 19(1), 42-52. https:// doi.org/10.1177/1073191111415365

Brewer, J. A., Elwafi, H. M., \& Davis, J. H. (2013). Craving to quit: Psychological models and neurobiological mechanisms of mindfulness training as treatment for addictions. Psychology of Addictive Behaviors : Journal of the Society of Psychologists in Addictive Behaviors, 27(2), 366-379. https://doi. org/10.1037/a0028490

Brooks, S. K., Webster, R. K., Smith, L. E., Woodland, L., Wessely, S., Greenberg, N., \& Rubin, G. J. (2020). The psychological impact of quarantine and how to reduce it : Rapid review of the evidence. The Lancet, 395(10227), 912-920. https://doi.org/10.1016/S0140-6736(20)30460-8

Brown, K. W., \& Ryan, R. M. (2003). The benefits of being present : Mindfulness and its role in psychological well-being. Journal of Personality and Social Psychology, 84(4), 822-848. https://doi.org/10.1037/ 0022-3514.84.4.822

Byrne, S. P., Haber, P., Baillie, A., Costa, D. S. J., Fogliati, V., \& Morley, K. (2019). Systematic reviews of mindfulness and acceptance and commitment therapy for alcohol use disorder: Should we be using third wave therapies? Alcohol and Alcoholism (oxford, Oxfordshire), 54(2), 159-166. https://doi.org/ 10.1093/alcalc/agy089

Cappelleri, J. C., Bushmakin, A. G., McDermott, A. M., Sadosky, A. B., Petrie, C. D., \& Martin, S. (2009). Psychometric properties of a single-item scale to assess sleep quality among individuals with fibromyalgia. Health and Quality of Life Outcomes, 7, 54. https://doi.org/10.1186/1477-7525-7-54

Carlson, L. E., \& Brown, K. W. (2005). Validation of the Mindful Attention Awareness Scale in a cancer population. Journal of Psychosomatic Research, 58(1), 29-33. https://doi.org/10.1016/j.jpsychores. 2004.04.366

Cavicchioli, M., Movalli, M., \& Maffei, C. (2018). The clinical efficacy of mindfulness-based treatments for alcohol and drugs use disorders : A meta-analytic review of randomized and nonrandomized controlled trials. European Addiction Research, 24(3), 137-162. https://doi.org/10.1159/000490762

Chatzittofis, A., Karanikola, M., Michailidou, K., \& Constantinidou, A. (2021). Impact of the COVID19 Pandemic on the Mental Health of Healthcare Workers. International journal of environmental research and public health, 18(4), 1435. https://doi.org/10.3390/ijerph18041435

Chodkiewicz, J., Talarowska, M., Miniszewska, J., Nawrocka, N., \& Bilinski, P. (2020). Alcohol Consumption Reported during the COVID-19 Pandemic: The Initial Stage. International journal of environmental research and public health, 17(13), 4677. https://doi.org/10.3390/ijerph17134677

Clinchamps, M., Auclair, C., Prunet, D., Pfabigan, D., Lesage, F.-X., Baker, J. S., ... Dutheil, F. (2021). Burnout among hospital non-healthcare staff : Influence of job demand-control-support, and effortreward imbalance. Journal of Occupational and Environmental Medicine, 63(1), e13-e20. https://doi. org/10.1097/JOM.0000000000002072

Conversano, C., Di Giuseppe, M., Miccoli, M., Ciacchini, R., Gemignani, A., \& Orrù, G. (2020). Mindfulness, Age and Gender as Protective Factors Against Psychological Distress During COVID-19 Pandemic. Frontiers in psychology, 11, 1900. https://doi.org/10.3389/fpsyg.2020.01900

de Boer, A. G. E. M., van Lanschot, J. J. B., Stalmeier, P. F. M., van Sandick, J. W., Hulscher, J. B. F., de Haes, J. C. J. M., \& Sprangers, M. A. G. (2004). Is a single-item visual analogue scale as valid, reliable and responsive as multi-item scales in measuring quality of life? Quality of Life Research: An 
International Journal of Quality of Life Aspects of Treatment, Care and Rehabilitation, 13(2), 311320. https://doi.org/10.1023/B:QURE.0000018499.64574.1f

Dillard, A. J., \& Meier, B. P. (2021). Trait mindfulness is negatively associated with distress related to COVID-19. Personality and individual differences, 179, 110955. https://doi.org/10.1016/j.paid.2021. 110955

Durand, A.-C., Bompard, C., Sportiello, J., Michelet, P., \& Gentile, S. (2019). Stress and burnout among professionals working in the emergency department in a French university hospital : Prevalence and associated factors. Work (Reading, Mass.), 63(1), 57-67. https://doi.org/10.3233/WOR-192908

Etter, J. F., Duc, T. V., \& Perneger, T. V. (1999). Validity of the Fagerström Test for Nicotine Dependence and of the Heaviness of Smoking Index among relatively light smokers. Addiction (abingdon, England), 94(2), 269-281. https://doi.org/10.1046/j.1360-0443.1999.94226910.x

Evans, S., Alkan, E., Bhangoo, J. K., Tenenbaum, H., \& Ng-Knight, T. (2021). Effects of the COVID-19 lockdown on mental health, wellbeing, sleep, and alcohol use in a UK student sample. Psychiatry Research, 298, 113819. https://doi.org/10.1016/j.psychres.2021.113819

Fiorillo, A., Sampogna, G., Giallonardo, V., Del Vecchio, V., Luciano, M., Albert, U., ... Volpe, U. (2020). Effects of the lockdown on the mental health of the general population during the COVID-19 pandemic in Italy : Results from the COMET collaborative network. European Psychiatry, 63(1). https:// doi.org/10.1192/j.eurpsy.2020.89

Freudenthaler, L., Turba, J. D., \& Tran, U. S. (2017). Emotion regulation mediates the associations of mindfulness on symptoms of depression and anxiety in the general population. Mindfulness, 8(5), 13391344. https://doi.org/10.1007/s12671-017-0709-y

Garland, E. L., \& Howard, M. O. (2018). Mindfulness-based treatment of addiction: current state of the field and envisioning the next wave of research. Addiction science \& clinical practice, 13(1), 14. https://doi. org/10.1186/s13722-018-0115-3

Gemmell, L. A., Terhorst, L., Jhamb, M., Unruh, M., Myaskovsky, L., Kester, L., \& Steel, J. L. (2016). Gender and racial differences in stress, coping, and health-related quality of life in chronic kidney disease. Journal of Pain and Symptom Management, 52(6), 806-812. https://doi.org/10.1016/j.jpainsymman. 2016.05.029

Gendall, P., Hoek, J., Stanley, J., Jenkins, M., \& Every-Palmer, S. (2021). Changes in tobacco use during the 2020 COVID-19 lockdown in New Zealand. Nicotine \& Tobacco Research: Official Journal of the Society for Research on Nicotine and Tobacco. https://doi.org/10.1093/ntr/ntaa257

Grogan, S., Walker, L., McChesney, G., Gee, I., Gough, B., \& Cordero, M. I. (2020). How has COVID-19 lockdown impacted smoking? A thematic analysis of written accounts from UK smokers. Psychology \& Health, 1-17. https://doi.org/10.1080/08870446.2020.1862110

Grossman, E. R., Benjamin-Neelon, S. E., \& Sonnenschein, S. (2020). Alcohol Consumption during the COVID-19 Pandemic: A Cross-Sectional Survey of US Adults. International journal of environmental research and public health, 17(24), 9189. https://doi.org/10.3390/ijerph17249189

Haesebaert, F., Haesebaert, J., Zante, E., \& Franck, N. (2020). Who maintains good mental health in a locked-down country? A French nationwide online survey of 11,391 participants. Health \& Place, 66, 102440. https://doi.org/10.1016/j.healthplace.2020.102440

Hall, L. H., Johnson, J., Watt, I., Tsipa, A., \& O’Connor, D. B. (2016). Healthcare Staff Wellbeing, Burnout, and Patient Safety: A Systematic Review. PloS one, 11(7), e0159015. https://doi.org/10.1371/journal. pone. 0159015

Hanley, A., Garland, E. L., \& Black, D. S. (2014). Use of mindful reappraisal coping among meditation practitioners. Journal of Clinical Psychology, 70(3), 294-301. https://doi.org/10.1002/jclp.22023

Heatherton, T. F., Kozlowski, L. T., Frecker, R. C., \& Fagerström, K. O. (1991). The Fagerström Test for Nicotine Dependence: A revision of the Fagerström Tolerance Questionnaire. British Journal of Addiction, 86(9), 1119-1127. https://doi.org/10.1111/j.1360-0443.1991.tb01879.x

Heppner, W. L., Spears, C. A., Correa-Fernández, V., Castro, Y., Li, Y., Guo, B., ... Wetter, D. W. (2016). Dispositional mindfulness predicts enhanced smoking cessation and smoking lapse recovery. Annals of Behavioral Medicine: A Publication of the Society of Behavioral Medicine, 50(3), 337-347. https://doi. org/10.1007/s12160-015-9759-3

Hobfoll, S. E., Dunahoo, C. L., Ben-Porath, Y., \& Monnier, J. (1994). Gender and coping : The dual-axis model of coping. American Journal of Community Psychology, 22(1), 49-82. https://doi.org/10.1007/ BF02506817

Hosmer, D., W., \& Lemeshow, S. (2000). Applied Logistic Regression (Second edition). John Wiley \& Sons, Inc. Consulté à l'adresse https://onlinelibrary.wiley.com/doi/book/https://doi.org/10.1002/0471722146

Huang, Y., \& Zhao, N. (2020). Generalized anxiety disorder, depressive symptoms and sleep quality during COVID-19 outbreak in China: A web-based cross-sectional survey. Psychiatry Research, 288, 112954. https://doi.org/10.1016/j.psychres.2020.112954 
Jacob, L., Smith, L., Armstrong, N. C., Yakkundi, A., Barnett, Y., Butler, L., ... Tully, M. A. (2021). Alcohol use and mental health during COVID-19 lockdown : A cross-sectional study in a sample of UK adults. Drug and Alcohol Dependence, 219, 108488. https://doi.org/10.1016/j.drugalcdep.2020.108488

Jaiswal, S., Muggleton, N. G., Juan, C.-H., \& Liang, W.-K. (2019). Indices of association between anxiety and mindfulness : A guide for future mindfulness studies. Personality Neuroscience, 2. https:// doi.org/10.1017/pen.2019.12

Jermann, F., Billieux, J., Larøi, F., d’Argembeau, A., Bondolfi, G., Zermatten, A., \& Van der Linden, M. (2009). Mindful Attention Awareness Scale (MAAS): Psychometric properties of the French translation and exploration of its relations with emotion regulation strategies. Psychological Assessment, 21(4), 506-514. https://doi.org/10.1037/a0017032

Jo, S.-H., Koo, B.-H., Seo, W.-S., Yun, S.-H., \& Kim, H.-G. (2020). The psychological impact of the coronavirus disease pandemic on hospital workers in Daegu South Korea. Comprehensive Psychiatry, 103, 152213. https://doi.org/10.1016/j.comppsych.2020.152213

Jones, D. R., Lehman, B. J., Noriega, A., \& Dinnel, D. L. (2019). The effects of a short-term mindfulness meditation intervention on coping flexibility. Anxiety, Stress, and Coping, 32(4), 347-361. https://doi.org/10.1080/10615806.2019.1596672

Kamboj, S. K., Irez, D., Serfaty, S., Thomas, E., Das, R. K., \& Freeman, T. P. (2017). Ultra-brief mindfulness training reduces alcohol consumption in at-risk drinkers: A randomized double-blind active-controlled experiment. International Journal of Neuropsychopharmacology, 20(11), 936947. https://doi.org/10.1093/ijnp/pyx064

Kansoun, Z., Boyer, L., Hodgkinson, M., Villes, V., Lançon, C., \& Fond, G. (2019). Burnout in French physicians : A systematic review and meta-analysis. Journal of Affective Disorders, 246, 132-147. https://doi.org/10.1016/j.jad.2018.12.056

Karyadi, K. A., VanderVeen, J. D., \& Cyders, M. A. (2014). A meta-analysis of the relationship between trait mindfulness and substance use behaviors. Drug and Alcohol Dependence, 143, 1-10. https:// doi.org/10.1016/j.drugalcdep.2014.07.014

Klemperer, E. M., West, J. C., Peasley-Miklus, C., \& Villanti, A. C. (2020). Change in tobacco and electronic cigarette use and motivation to quit in response to COVID-19. Nicotine \& Tobacco Research: Official Journal of the Society for Research on Nicotine and Tobacco, 22(9), 1662-1663. https:// doi.org/10.1093/ntr/ntaa072

Kozak, K., Lucatch, A. M., Lowe, D. J. E., Balodis, I. M., MacKillop, J., \& George, T. P. (2019). The neurobiology of impulsivity and substance use disorders : Implications for treatment. Annals of the New York Academy of Sciences, 1451(1), 71-91. https://doi.org/10.1111/nyas.13977

Lange, M., Joo, S., Couette, P.-A., Le Bas, F., \& Humbert, X. (2021). Impact on mental health of the COVID-19 outbreak among general practitioners during the sanitary lockdown period. Irish Journal of Medical Science. https://doi.org/10.1007/s11845-021-02513-6

Li, W., Howard, M. O., Garland, E. L., McGovern, P., \& Lazar, M. (2017). Mindfulness treatment for substance misuse : A systematic review and meta-analysis. Journal of Substance Abuse Treatment, 75, 62-96. https://doi.org/10.1016/j.jsat.2017.01.008

Loucks, E. B., Britton, W. B., Howe, C. J., Eaton, C. B., \& Buka, S. L. (2015). Positive associations of dispositional mindfulness with cardiovascular health: The New England Family Study. International Journal of Behavioral Medicine, 22(4), 540-550. APA PsycInfo (2015-38218-011). https:// doi.org/10.1007/s12529-014-9448-9

Lutz, J., Herwig, U., Opialla, S., Hittmeyer, A., Jäncke, L., Rufer, M., ... Brühl, A. B. (2014). Mindfulness and emotion regulation-An fMRI study. Social Cognitive and Affective Neuroscience, 9(6), 776-785. https://doi.org/10.1093/scan/nst043

Maglione, M. A., Maher, A. R., Ewing, B., Colaiaco, B., Newberry, S., Kandrack, R., ... Hempel, S. (2017). Efficacy of mindfulness meditation for smoking cessation : A systematic review and metaanalysis. Addictive Behaviors, 69, 27-34. https://doi.org/10.1016/j.addbeh.2017.01.022

Mattila, E., Peltokoski, J., Neva, M. H., Kaunonen, M., Helminen, M., \& Parkkila, A.-K. (2021). COVID-19: Anxiety among hospital staff and associated factors. Annals of Medicine, 53(1), 237246. https://doi.org/10.1080/07853890.2020.1862905

McFarland, D. C., \& Hlubocky, F. (2021). Therapeutic strategies to tackle burnout and emotional exhaustion in frontline medical staff : Narrative review. Psychology Research and Behavior Management, 14, 1429-1436. https://doi.org/10.2147/PRBM.S256228

Müller, G., Pfinder, M., Schmahl, C., Bohus, M., \& Lyssenko, L. (2019). Cost-effectiveness of a mindfulness-based mental health promotion program : Economic evaluation of a nonrandomized controlled trial with propensity score matching. BMC Public Health, 19(1), 1309. https://doi.org/10. 1186/s12889-019-7585-4 
Nosratabadi, M., Halvaiepour, Z., \& Abootorabi, S. H. (2017). Craving for cigarette smoking among male adolescents in Isfahan based on mindfulness and emotional self-regulation. International Journal of Adolescent Medicine and Health, 30(6), 20160113. https://doi.org/10.1515/ ijamh-2016-0113

Oikonomou, M. T., Arvanitis, M., \& Sokolove, R. L. (2017). Mindfulness training for smoking cessation : A meta-analysis of randomized-controlled trials. Journal of Health Psychology, 22(14), 1841-1850. https://doi.org/10.1177/1359105316637667

Panda, P. K., Gupta, J., Chowdhury, S. R., Kumar, R., Meena, A. K., Madaan, P., Sharawat, I. K., \& Gulati, S. (2021). Psychological and Behavioral Impact of Lockdown and Quarantine Measures for COVID-19 Pandemic on Children, Adolescents and Caregivers: A Systematic Review and Meta-Analysis. Journal of tropical pediatrics, 67(1), fmaa122. https://doi.org/10.1093/tropej/fmaa122

Peters, J. R., Erisman, S. M., Upton, B. T., Baer, R. A., \& Roemer, L. (2011). A preliminary investigation of the relationships between dispositional mindfulness and impulsivity. Mindfulness, 2(4), 228-235. https://doi.org/10.1007/s12671-011-0065-2

Rodriguez-Vega, B., Palao, Á., Muñoz-Sanjose, A., Torrijos, M., Aguirre, P., Fernández, A., ... Bayón, C. (2020). Implementation of a mindfulness-based crisis intervention for frontline healthcare workers during the COVID-19 outbreak in a public general hospital in Madrid, Spain. Frontiers in Psychiatry, 11, 562578. https://doi.org/10.3389/fpsyt.2020.562578

Rossinot, H., Fantin, R., \& Venne, J. (2020). Behavioral Changes During COVID-19 Confinement in France: A Web-Based Study. International journal of environmental research and public health, 17(22), 8444. https://doi.org/10.3390/ijerph17228444

Ruiz-Fernández, M. D., Ortíz-Amo, R., Ortega-Galán, Á. M., Ibáñez-Masero, O., Rodríguez-Salvador, M. D. M., \& Ramos-Pichardo, J. D. (2020). Mindfulness therapies on health professionals. International Journal of Mental Health Nursing, 29(2), 127-140. https://doi.org/10.1111/inm.12652

Smith, J. P., \& Book, S. W. (2008). Anxiety and substance use disorders : A review. The Psychiatric times, 25(10), 19-23.

Sourial, N., Wolfson, C., Zhu, B., Quail, J., Fletcher, J., Karunananthan, S., .. Bergman, H. (2010). Correspondence analysis is a useful tool to uncover the relationships among categorical variables. Journal of clinical epidemiology, 63(6), 638-646. https://doi.org/10.1016/j.jclinepi.2009.08.008

Spinelli, C., Wisener, M., \& Khoury, B. (2019). Mindfulness training for healthcare professionals and trainees : A meta-analysis of randomized controlled trials. Journal of Psychosomatic Research, 120, 29-38. https://doi.org/10.1016/j.jpsychores.2019.03.003

Szeto, E. H., Schoenmakers, T. M., van de Mheen, D., Snelleman, M., \& Waters, A. J. (2019). Associations between dispositional mindfulness, craving, and drinking in alcohol-dependent patients : An ecological momentary assessment study. Psychology of Addictive Behaviors: Journal of the Society of Psychologists in Addictive Behaviors, 33(5), 431-441. https://doi.org/10.1037/adb0000473

Tapper, K. (2018). Mindfulness and craving : Effects and mechanisms. Clinical Psychology Review, 59, 101-117. https://doi.org/10.1016/j.cpr.2017.11.003

Vanderbruggen, N., Matthys, F., Van Laere, S., Zeeuws, D., Santermans, L., Van den Ameele, S., \& Crunelle, C. L. (2020). Self-reported alcohol, tobacco, and cannabis use during COVID-19 lockdown measures : Results from a web-based survey. European Addiction Research, 26(6), 309-315. https:// doi.org/10.1159/000510822

Vizheh, M., Qorbani, M., Arzaghi, S. M., Muhidin, S., Javanmard, Z., \& Esmaeili, M. (2020). The mental health of healthcare workers in the COVID-19 pandemic : A systematic review. Journal of Diabetes and Metabolic Disorders, 19(2), 1-12. https://doi.org/10.1007/s40200-020-00643-9

Wardell, J. D., Kempe, T., Rapinda, K. K., Single, A., Bilevicius, E., Frohlich, J. R.,... Keough, M. T. (2020). Drinking to cope during COVID-19 pandemic: The role of external and internal factors in coping motive pathways to alcohol use, solitary drinking, and alcohol problems. Alcoholism, Clinical and Experimental Research, 44(10), 2073-2083. https://doi.org/10.1111/acer.14425

Xiong, J., Lipsitz, O., Nasri, F., Lui, L. M. W., Gill, H., Phan, L., .. McIntyre, R. S. (2020). Impact of COVID-19 pandemic on mental health in the general population : A systematic review. Journal of Affective Disorders, 277, 55-64. https://doi.org/10.1016/j.jad.2020.08.001

Zgierska, A. E., Burzinski, C. A., Mundt, M. P., McClintock, A. S., Cox, J., Coe, C. L., ... Fleming, M. F. (2019). Mindfulness-based relapse prevention for alcohol dependence : Findings from a randomized controlled trial. Journal of Substance Abuse Treatment, 100, 8-17. https://doi.org/10.1016/j.jsat.2019. 01.013

Publisher's Note Springer Nature remains neutral with regard to jurisdictional claims in published maps and institutional affiliations. 